\title{
Computational Technique for Effectiveness of Treatments Used in Curing SARS-CoV-2
}

\author{
Wael Alosaimi ${ }^{1}$, Rajeev Kumar ${ }^{2, *}$, Abdullah Alharbi ${ }^{1}$, Hashem Alyami $^{3}$, Alka Agrawal ${ }^{4}$, \\ Gaurav Kaithwas ${ }^{5}$, Sanjay Singh ${ }^{6}$ and Raees Ahmad Khan ${ }^{4}$
}

\footnotetext{
${ }^{1}$ Department of Information Technology, College of Computers and Information Technology, Taif University, P. O. Box 11099, Taif 21944, Saudi Arabia

${ }^{2}$ Department of Computer Application, Shri Ramswaroop Memorial University, Barabanki, 225003, Uttar Pradesh, India

${ }^{3}$ Department of Computer Science, College of Computers and Information Technology, Taif University, P. O. Box 11099, Taif 21944, Saudi Arabia

${ }^{4}$ Department of Information Technology, Babasaheb Bhimrao Ambedkar University, Lucknow, 226025, Uttar Pradesh, India

${ }^{5}$ Department of Pharmaceutical Science, Babasaheb Bhimrao Ambedkar University, Lucknow, 226025, Uttar Pradesh, India

${ }^{6}$ Hon'ble Vice Chancellor, Babasaheb Bhimrao Ambedkar University, Lucknow, 226025, Uttar Pradesh, India

${ }^{*}$ Corresponding Author: Rajeev Kumar. Email: rs0414@gmail.com

Received: 08 January 2021; Accepted: 09 February 2021
}

\begin{abstract}
COVID-19 pandemic has unleashed an unprecedented humanitarian crisis in the world at present. With each passing day, the number of patients afflicted with Severe Acute Respiratory Syndrome Coronavirus 2 (SARS-CoV-2) is rising at an alarming pace, so much so that some countries are now combating the second wave of the contagion. As the death ratio due to the Virus increases, the medical fraternity and pharmacologists are working relentlessly to identify and prescribe a standardized and effective course of treatment for treating COVID-19 patients. However, medical specialists are confused about opting for the most efficacious course of treatment because the patients infected with this virus have varied symptoms at different stages. In this league, our research study attempts to conduct an empirical analysis to identify which course of treatment is the most effective and preferred one for the treatment of SARS-CoV-2. The study proposes to achieve this objective by employing a scientific computation based symmetrical methodology. The present study has adopted a well-established and highly effective Multi Criteria Decision Making (MCDM) approach named Hesitant Fuzzy Linguistic Term Sets based Analytical Hierarchy Process-Technique for Order of Preference by Similarity to Ideal Solution (HFLTS-AHP-TOPSIS) Methodology. The computation based symmetrical methodology evaluates the various selected course of treatments identified through different research articles and guidelines suggested by different countries, and evaluates them on the basis of opinions suggested by medical experts (including doctors, industry experts, and others) and practitioners. Thus, the results drawn are highly corroborative and can be used as an authentic reference for future initiatives being undertaken in this domain. Our research investigation outlines a systematically assessed and scientifically validated ranking for various courses of treatments used in SARS-CoV-2 treatment and proposes to be an effective reckoner in the attempts to dispel the ambiguities surrounding the cure
\end{abstract}

This work is licensed under a Creative Commons Attribution 4.0 International License, which permits unrestricted use, distribution, and reproduction in any medium, provided the original work is properly cited. 
of SARS-CoV-2. Additionally, to authenticate the results of our analysis, we performed the sensitivity analysis (robustness analysis), marginal mean assessment and comparison analysis.

Keywords: SARS-CoV-2; hesitant fuzzy linguistic term sets; computational based AHP-TOPSIS method

\section{Introduction}

In December 2019, a novel virus with a unique protein bonding and spreading patterns emerged as a disaster in Wuhan, China. Thereafter, in early January 2020, the World Health Organization (WHO) declared the outbreak of this virus a Global pandemic, defining the name of the unknown novel virus as the Severe Acute Respiratory Syndrome Corona virus (SARS-CoV-2). Further, COVID-19 terminology is used for defining the disease caused by virus SARS-CoV-2. With no vaccine as a preventive mechanism and no unified and standard medicine or medication process [1] available against this pandemic, the world is bracing for even more volatile times ahead as the COVID-19 cases continue to mount. As cited by the medical experts, the biggest challenge in treating this disease is the unpredictable nature of the virus [2]. Those who are afflicted with COVID-19 show a varied range of symptoms; while the COVID-19 cases can range from mild to severe, there are some patients that remain entirely asymptomatic and continue to be a shedder of the virus without being affected themselves. This makes COVID-19 a highly fatal disease. Even the doctors treating the COVID-19 patients are grappling with the difficulties of prescribing the initial medication and drug formulation that would suit the patients and serve as an effective remedy.

As of now, quarantine and lockdown/shutdown have been strongly recommended as the only preventive means to break the chain of transmission of SARS-CoV-2. However, they are not a permanent solution [3] of the problem. Several investigations by different laboratories and individual researchers towards developing an effective vaccine and instituting a standardized course of medication to cure COVID-19 is already underway. Some famous institutions that are effectively working towards vaccine preparation are Oxford University, a pharmaceutical enterprise Inovio, US laboratory, a central place of United States vaccine development, besides others, whose vaccine samples are now undergoing trials.

At present the doctors are performing symptomatic treatment of patients, i.e., the prescribed medication for treating patients in the initial phase of disease depending on the symptoms of the patients [2]. Various researchers are working on finding an effective single course of treatment for the SARS-CoV-2 virus with the help of previously identified and well established treatment therapies. This highly ambivalent context in treating Corona cases becomes a premise for an in-depth research query which must summarize the different courses of treatment of SARS-CoV-2 infected cases so as to portray clarity and ambiguity-free remedial interventions. Hence addressing this research possibility, the proposed study tries to summarize and then measure the effectiveness of the various well established courses of treatment that are under trial or research for treating SARS-CoV-2 infected patients. The quantitative assessment has been done by using a computational method of Hesitant Fuzzy Linguistic Term Sets (HFLTS) based Analytical Hierarchy Process-Technique for Order of Preference by Similarity to Ideal Solution (AHP-TOPSIS). This type of categorization of treatment procedures is intended to facilitate the efforts of doctors who can draw upon the available data for the most preferred course of treatment to follow while prescribing medication for SARS-CoV-2 infected cases.

The heterogeneity in curing COVID-19 patients because of the lack of a standard treatment therapy remains a major concern for the medical fraternity. The authors of this study attempt to simplify this situation by adopting a Multi-Criteria Decision Making (MCDM) Methodology to solve and reduce the 
stated complexities for medical experts. MCDM approach is a validated and strong scientific methodology that provides precise and effective results in critical cases of multi-criteria decision. Many MCDM approaches are available in the current era. According to Wikipedia there are $30 \mathrm{MCDM}$ approaches. Analytical Hierarchy Process (AHP) is a famous and a widely used methodology in MCDM. The authors used a computational method of HFLTS based AHP-TOPSIS hybrid technique in this study. Several experts have been able to determine reliable and optimum outcomes by using HFLTS-TOPSIS approach. However, the precise criteria for the quantitative assessment of qualitative attribute weights has not been given yet.

The HFLTS-AHP technique allows decision-makers to systemically weigh the characteristics, thereby removing any complexities and ambiguities in the evaluation. Consistent factor weights are obtained with the aid of hesitant-fuzzy numbers and pair-wise comparisons. However, because of the monotonous equations and a large number of pairs of comparisons for several choices, the HFLTS-AHP approach is inefficient. Therefore, the authors suggest that the hybrid method of HFLTS-AHP-TOPSIS should be used to determine the effect of alternatives in a reasonable time and without convoluted assessments. Thus to tackle this problem in the current evaluation, HFLTS process is proposed. This technique will help the decision-makers to opt for their desired valuation for factors. This methodology was introduced and discussed by Rodriguez et al. [4]. The methodology helps the examiners to contain the hesitant linguistics term sets and the calculation provides more accurate results in the comparison of the other MCDM techniques. Moreover, in the context of this paper, the authors adopted a hybrid HFLTS-AHP-TOPSIS methodology for evaluating the effectiveness of the various courses of treatment for COVID-19. The methodology has been described in the next section.

The rest of this paper is organized as: the second section of the paper portrays a view on previous statistics of the Coronavirus for plot understanding, and the third section of the paper illustrates the previous literature examination related to drug classification for COVID-19 through a computational approach. The fourth section of the paper displays and describes the selected preventive drugs for the Coronavirus, and after that, sections fifth and sixth describe the adopted methodology as well as its numeric evaluation, respectively. The seventh section of the study discusses the evaluated results from various perspective, while section eight concludes the paper by discussing its limitations and benefits.

Some of the significant contributions of this study are outlined below:

- The study performs a scientific computational MCDM method to evaluate the effectiveness of the various selected treatment procedures for SARS-CoV-2.

- The study provides a systematic path and understanding of the most effective course of treatment for curing the COVID-19 patients.

- As a contribution to the research community, the paper provides an ideal methodology with conclusive results that can be utilized by any researcher in the future to assess a similar type of evaluation.

These contributions are described and discussed in following sections of the paper.

\section{Materials \& Methods}

\subsection{Previous Literature Examination}

Categorization and the assessment of the effectiveness of a course of treatment for Corona cases required an expansive search and review of existing research studies done in this domain. Thus, for outsourcing the most relevant references, we categorized key terms for reviewing the literature. The keywords selected for the database search are described in Tab. 1. 
Table 1: Keywords and database search

\begin{tabular}{lll}
\hline $\begin{array}{l}\text { Term } \\
\text { Level }\end{array}$ & Keyword & Data Repository \\
\hline Primary & $\begin{array}{l}\text { Course of Treatment, Drug Prioritization, } \\
\text { Treatment selection. }\end{array}$ & $\begin{array}{l}\text { PubMed, IEEE Xplore, Google Scholar, } \\
\text { Science Direct }\end{array}$ \\
Secondary & $\begin{array}{l}\text { Multi Criteria Decision Making, Modeling } \\
\text { Computational Modeling. }\end{array}$ & \\
Third & Disease, COVID-19, SARS-CoV-2. & \\
\hline
\end{tabular}

These keywords helped us to identify and extract the relevant articles. However, we could outsource very few articles that are related to our research query. Although numerous research endeavours are underway on COVID-19, unfortunately, there is no specific literature on categorization and prioritization for evaluating the various courses of treatment and ranking them through an MCDM approach. The few studies that are somewhat similar to our work have been summarized in the following paragraphs.

Studies [5-7] discuss about the enhancement of the adopted methodology for assessment and propose an algorithm that talks about the balance in linguistic terms sets and their management. In this league, studies $[8,9]$ also helped us in choosing the right approach to conduct our empirical investigations based on the HFLTS-AHP-TOPSIS methodology.

Chen et al. presented a decision support model based on fuzzy logic and ontology theory that helps the physicians and doctors in suggesting drugs for diabetic patients. The model has an accuracy of $80 \%$, according to experiments and suggestions [10]. An analysis of the proposed model by Chen et al. describes that the model was based on fuzzy set theory for prioritization and recommendation. The model is extremely helpful for the doctors' reference and also became a premise for our study which aims at designing a drug prioritization approach to categorize the drugs according to their effectiveness in curing SARS-CoV-2.

In the same league, Jumi Wang proposed a paper of computation drug repurposing for the fast treatment of the Coronavirus. The paper provides a useful approach for modeling the drug patterns and identifying the possible drug structure that can work as a vaccine for SARS-CoV-2 [11].

Ren et al. proposed a Z-number based hesitant fuzzy approach for selecting the medicine for COVID-19. The model proposed by the researcher in the study adopted a hesitant fuzzy approach with the addition of Z-numbers that gives more accuracy to its results [12]. The results of the implementation showed that though the model is effective, it can identify only a single drug or treatment at once. This implies that the model evaluates the accuracy of treatment individually after its testing.

There are several research studies that describe the drugs and their possible outcome for treating COVID-19 patients. Hence, there is a growing need to collate these recommended drugs and all possible treatment procedures that are being prescribed by the doctors. Moreover, a systematic categorization of these drugs, in the order of preference for use, will also expedite the healthcare initiatives being taken in this regard. The analysis of previous literature studies corroborated the fact that there is yet no research study that classifies and, thereafter prioritizes various tested courses of treatments for COVID-19 according to their effectiveness by a scientific computational methodology. Thus addressing this research possibility, we converged our research onto enlisting the various drugs and alternative therapy approaches that are being practiced by the doctors to cure COVID-19 cases currently. An in-depth analysis of the same has been chronicled in the ensuing segment. 


\subsection{Course of Treatment against COVID-19 Pandemic}

COVID-19 pandemic has been declared a massive health emergency. In the efforts to reduce mortality rate and increase the recovery rate of the patients, the doctors and researchers in the healthcare field are pursuing therapeutic procedures which they believe are suited to the patient's body constitution. Hence, both Allopathy and Ayurveda courses of treatment for COVID-19 cases have been in use.

In the proposed study, we have analyzed the various studies that discussed the courses of treatment of COVID-19 and also garnered the opinions of medical experts on the same. These medical experts are from one of the leading and renowned medical institutes in India, SGPGI (Sanjay Gandhi Postgraduate Institute of Medical Sciences) in Lucknow. A questionnaire containing the questions related to the research problem is given to more than 100 medical experts and doctors and 75 valid responses were collected. The responses were used to create the hierarchy in Fig. 1. After that, we developed a hierarchical model of the selected treatment procedures. The model of possible preventive drugs, prepared by authors, for evaluation is displayed in also Fig. 1.

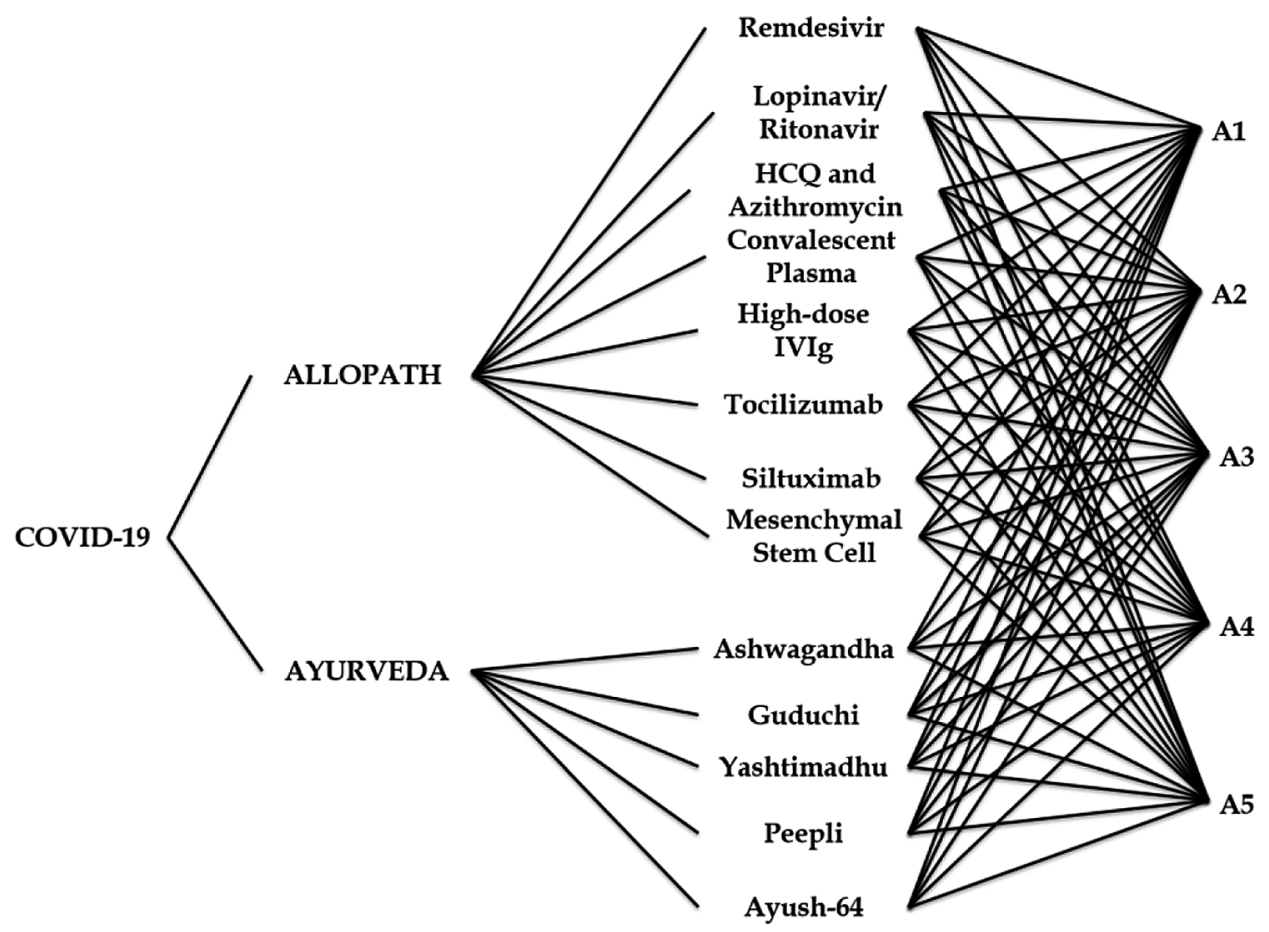

Figure 1: Hierarchical view of selected preventive drugs

The Fig. 1 also has associate alternatives represented as $A 1$ to $A 5$ that refer to various small projects of selected hospitals on which the simulation experiments are implemented by the researchers of this study. Notably, the study only summarized the Allopath and Ayurveda as a primary treatment pattern due to their high effect and significance in the modern treatment procedures.

\subsubsection{Allopathy}

Allopathy is a quick, effective, and modern [13] way of treatment. The effects and results of allopathic drugs are globally acceptable and efficacious. We selected 8 treatment courses that are currently being used for Coronavirus treatment for our hierarchical model. The therapy selection is performed by experts' suggestions and literature assessment. The enumeration of the same is scribed below: 
- Remdesivir: The role of remdesivir $\left(\mathrm{C}_{17} \mathrm{H}_{35} \mathrm{~N}_{6} \mathrm{O}_{8} \mathrm{P}\right)$ for SARS-CoV-2 treatment is under investigation by various research organizations and experts. It contains a nucleotide analog associated with a highefficiency ratio as antiviral. A study that is performed on COVID-19 patients with remdesivir as compassionate-use basis medicine shows that 61 COVID-19 patients are administered at least one dose of this medicine during their treatment process. 8 patient's data could not be analyzed due to some technical error, however the analysis of the data of the remaining patients displayed that the improvement ratio of patients is $68 \%$ in all [14]. The concluding remarks of study, as well as experts, are that remdesivir is an effective drug against SARS-CoV-2.

- Lopinavir/Ritonavir: The medicine $\left(\mathrm{C}_{37} \mathrm{H}_{48} \mathrm{~N}_{6} \mathrm{O}_{5} \mathrm{~S}_{2}\right)$ is essentially used in treating Human Immunodeficiency Virus/Acquired Immunodeficiency Syndrome (HIV/AIDS) however experts and examinations illustrate that the drug has the potential to treat corona patients. A study of lopinavir/ritonavir is conducted in a random, open-label, controlled condition on positive COVID-19 patients. Further, another study with the same medicine shows that 47 COVID-19 patients are selected for examination where 43 patients are treated with lopinavir/ritonavir and 5 patients are treated with the standard therapy process. Results showed that return to the normal body temperature is achieved faster in the lopinavir/ritonavir treatment group [15]. The researchers believe that examined results and the effect of the treatment on day-to-day basis shows that future research and trials with the lopinavir/Ritonavir can yield better outcomes for treating COVID-19 patients.

- Hydroxychloroquine (HCQ) and Azithromycin: HCQ and azithromycin have efficient and effective results [16] in SARS-CoV-2 treatment. Gautret et al. presented a study with 26 COVID-19 patients. The study displayed that $70 \%$ of the patients registered negative PCR during treatment with $200 \mathrm{mg}$ HCQ three times a day. Azithromycin is added only in 6 patients' treatment routine and showed highly effective results in treating SARS-CoV-2 [16]. Further, with the help of research outcomes, several doctors have started the use of HCQ and azithromycin against Coronavirus.

- Convalescent Plasma: It is an experimental however effective therapy for SARS-CoV-2. Convalescent plasma is a method where doctors use the blood of recovered patients of COVID-19 to treat active patients. Patients who recover from SARS-CoV-2 develop antibodies in their blood and medical practitioners use the blood to treat COVID-19 patients. This therapy is currently being used across the globe. Particularly, in Delhi, India, the results are very satisfying [17] and highly recommendable. To quote the observations of senior doctor and medical expert, Dr. Budhirja, "Plasma therapy is the most effective and old treatment course that has had immense beneficial results in previous virus attacks also" [17]. In order to analyze the actual effect of the therapy, the treatment process is adopted for 5 COVID-19 patients. The results showed that the body temperature became normal within 3 days of treatment in 4 to 5 patients. Additionally, the Sequential Organ Failure Assessment (SOFA) score also decreased in these patients. After 12 days of transfusion, the viral load also became negative [18]. Conclusively it is shown that the therapy has an effective and positive outcome however researchers believe that the process of treatment needs more intensive scrutiny and enhancement.

- High-Dose Intravenous Immunoglobulin (IVIg): IVIg is the process of treating patients with a blood serum that is prepared from 1000 and 15000 donors per batch. The prepared serum has antibody characteristics and works as an anti-disease medicine in the body [19]. Furthermore, Cao et al. [20] proposed a study of treatment where 3 severe corona patients are treated by the high dose of IVIg. The results of the study showed that all 3 patients are successfully treated.

- Tocilizumab: It is an immunosuppressive drug that is frequently used in treating rheumatoid arthritis (RA) and systemic juvenile idiopathic arthritis. Xu et al. found that SARS-CoV-2 attack Interlukin 6 (IL-6) pathway in patient body. Additionally, they tried to treat patients with tocilizumab due to its 
high effective ratio against interleukin-6 receptor (IL-6R). The analysis of the treatment process illustrated that the temperature of the body becomes normal on the first day of the treatment and other symptoms are also effectively controlled and reduced. After 5 days of treatment through tocilizumab, 15 to 20 patients' oxygen intake became lower. No adverse effects and deaths are recorded during and after the treatment [21]. Thus, the drug is recommended for treating severe Corona cases.

- Siltuximab : Siltuximab directly targets the IL-6 in the body. It is used in the treatment of prostate cancer and other diseases. A study in the context of curing COVID-19 cases with this medicine tells that thirty patients are treated with siltuximab and results showed that the averages mean follow up value is 33.3 days in siltuximab treated patients [22]. The results are not accurately convincing and effective however experts believe that as asymptomatic preventive drugs, the siltuximab can work efficiently.

- Mesenchymal Stem Cells: Mesenchymal is a multipotent stem cell that is found in the bone marrow and responsible for repairing and creating skeletal tissues in the body. The transplantation of these cells can help in the treatment of Corona patients with promising results. In order to analyze the effect of Mesenchymal Stem Cells, a study is performed on 7 active COVID-19 patients. The study found that all the relevant symptoms of SARS-CoV-2 such as high fever, weakness, shortness of breath, and others got lower after 2-45 days of transplant [23]. Researchers believe [23] that mesenchymal stem cell transplant is an effective and safe approach for doctors to treat COVID-19 patients.

\subsubsection{Ayurveda}

Ayurveda is the oldest and purest form of treatment available from thousands years in India. Ayurvedic therapy combines 8 types of treatment [24] that treat every kind of disease and body part in it. Ayurvedic medication is popularly known to have no adverse effect and essentially eliminates the very root of the disease besides curing the ailing. Several experts and practitioners of alternative therapy believe that Ayurveda has the potential and possibilities [25] to treat COVID patients effectively. More significantly, Ayurveda drugs are also a highly preferred course of cure and are being prescribed [26] by both the Indian as well as other countries' doctors. Ayurveda is recognized as the oldest path of medication [26] that has its own significance and effect against various complex diseases.

Due to this intrinsic role of Ayurveda in modern medical science, the authors have also included an analysis of the ayurvedic therapies in the present study. US researchers approached the Indian embassy in America to interact with the Indian scientists and find an effective course of treatment for the SARSCoV-2 in Ayurveda [27-35]. Interestingly, the authors of the proposed study found that the first Corona patient from India undertook a regular treatment of Ayurveda in the absence of modern western medicine. The results of treatment are analyzed and described by Girija et al. The study tells that the patient's age was 43 and he had a previous medical history. Moreover, the patient had been taking ayurvedic therapy for his previous illness as well. The results showed that the symptoms of the Coronavirus are reducing day-by-day after treating the patient with ayurvedic medicines [36-41]. To establish a more authentic foreground for our research analysis on ayurvedic drugs, we referred to various authorized bodies [29,30] of Ayurveda to check their efficacy levels.

- Ashwagandha: It is an ayurvedic herb that is scientifically known as Withania somnifera. Ashwagandha has its own benefits from centuries in Indian traditional medicines. A research tells that ashwagandha has a high possibility ratio for treating Coronavirus patients. A study concluded that ashwagandha is a highly potent herb and can be used in treating Corona cases [29].

- Guduchi: Guduchi is the second ayurvedic drug that is under trial by the Indian government as a treatment course for COVID-19. Various other research initiatives [42] are focusing on guduchi for 
using it in COVID-19 treatment. Guduchi has high immunomodulatory characteristics that enhance and boost the immunity of the body as well as create a high antiviral system in the body [31]. The government as well as researchers strongly believe that proper and systematic research of Guduchi for corona treatment would provide positive and effective results.

- Yashtimadhu: It is another ayurvedic drug that is under examination by the Ministry of Ayush, India. Yashtimadhu, popularly known as Mulethi, has some highly advanced and beneficial effects in the main protease, spike protein, and RNA polymerase of Coronavirus and ACE2 receptor and furin protease. A study finds that yashtimadhu has a strong potential to treat the SARS-CoV-2 [32]. Research community strongly believes in drawing further upon this intrinsic property of the herb. Authors also find that this is widely adopted and has some effective results in curing corona virus [43].

- Peepli: Peepli is often used for treating cold and cough such as problems in traditional Indian therapy. The importance of peepli is described and derived in several research studies [33,34]. In order to treat Corona symptoms, the Ministry of Ayush, GOI has recommended further research on Peepli [35].

- Ayush-64: Ayush-64 is used for treating Malaria with no adverse effects. Allopathic medicines for Malaria have adverse effects on the human body. In order to use it in SARS-CoV-2 treatment, MOA has approved the trial of Ayush-64 because the symptoms of COVID and Malaria are slightly similar [29]. A research study also portrays the effect and use of this medicine in Coronavirus [44].

For a more illustrative frame of the selected course of treatments in this proposed study, we have summarized all selected studies in Tab. 2 on the basis of the path of Treatment (such as Allopathy or Ayurveda), experimental result availability that shows the condition of treatment course in the Coronavirus context, and then the evidence quality available in the case of the stated therapy for treating COVID patients. This type of classification is done with the help of medical experts associated with this study and literature examination.

Table 2: Summarization of selected courses of treatment

\begin{tabular}{llll}
\hline Course of Treatment & Path of Treatment & Experiment Availability & Evidence Quality \\
\hline Remdesivir & Allopath & YES & Low \\
Lopinavir/ritonavir & Allopath & YES & Very Low \\
Ashwagandha & Ayurveda & YES & Moderate \\
HCQ and Azithromycin & Allopath & YES & Low \\
Guduchi & Ayurveda & UT* & - \\
Yashtimadhu & Ayurveda & UT* & - \\
Convalescent plasma & Allopath & YES & Moderate \\
High-dose IVIg & Allopath & YES & Moderate \\
Tocilizumab & Allopath & YES & Low \\
Peepli & Ayurveda & UT* & - \\
Siltuximab & Allopath & YES & Low \\
Ayush-64 & Ayurveda & UT* & - \\
Mesenchymal Stem Cell & Allopath & YES & Moderate \\
\hline
\end{tabular}


Tab. 2 shows that no course of treatment has a high or very high range of evidence quality in their experiments against COVID. All Ayurvedic courses are under trial by authorities and their result will soon be out however various initial research and scientific outcomes [29,42-44] evidently portray that they have the possibility to be effective countermeasures against SARS-CoV-2. Further to this data, the evaluation of ranking based on effectiveness would help the doctors in prescribing a single treatment course for COVID-19 patients. For attaining this objective, the adopted methodology and detailed tabulations are mapped in the following segment.

\subsection{Adopted Methodology}

Since there are several therapies under trial or research for COVID-19, it became imperative to employ MCDM technique so as to make effective selection criteria for mapping the hierarchical model which would determine the most preferred course of treatment. In this regard, the AHP is one of the most trusted and verified techniques of MCDM. Comparison matrixes created in the process of evaluating AHP methodology gives accurate results, however many researchers and scientific theories believe that in some specific situation such as where alternatives are high in the count, the technique gives ambiguous results. To reduce this implication of methodology, we have included the TOPSIS approach that provides more precise results [36,37].

Additionally, keeping in view the seriousness of the subject discussed in the study authors incorporated the HFLTS methodology in adopting a fuzzy AHP-TOPSIS approach as an effective additional method for obtaining exact results sans any vagueness and implications. Thus HFLTS- AHP method is used to prioritize the various drugs for the Coronavirus based on weights. Thereafter, the HFLTS-TOPSIS method is used to select the best function or alternative for the selected treatments. The entire evaluation process of adopted methodology has been elucidated further in 15 steps tabulated below:

Step 1: Developing a tree structure of summarized and selected attributes or factors (in our case therapies) for appropriate calculation through it.

Step 2: Further, after developing the hierarchy for evaluating, it is important to understand what type of outcome is expected by the HFLTS-AHP process. To understand the different ranks and their linguistic terms for adopted methodology, Tab. 3, displayed below, is enlisted. Triangular fuzzy numbers displayed in Tab. 3 are values that are obtained by fuzzy set theory and used to rank the selected attributes by calculating expert's suggestions into a numerical form.

Table 3: Scale for HFLTS-AHP method

\begin{tabular}{llll}
\hline Rank & Abbreviation & Linguistic Term & Triangular Fuzzy Number \\
\hline 10 & AHI & Absolutely High Importance & $7.0000,9.0000,9.0000$ \\
9 & VHI & Very High Importance & $5.0000,7.0000,9.0000$ \\
8 & ESHI & Essentially High Importance & $3.0000,5.0000,7.0000$ \\
7 & WHI & Weakly High Importance & $1.0000,3.0000,5.0000$ \\
6 & EHI & Equally High Importance & $1.0000,1.0000,3.0000$ \\
5 & EE & Exactly Equal & $1.0000,1.0000,1.0000$ \\
4 & ELI & Equally Low Importance & $0.3300,1.0000,1.0000$ \\
3 & WLI & Weakly Low Important & $0.2000,0.3300,1.0000$ \\
2 & ESLI & Essentially Low Importance & $0.1400,0.2000,0.3300$ \\
1 & VLI & Very Low Importance & $0.1100,0.1400,0.2000$ \\
0 & ALI & Absolutely Low Importance & $0.1100,0.1100,0.1400$ \\
\hline
\end{tabular}


Step 3: With reference to the step 2 above \& [41], suppose T0 (Lowest TFN Value) has the lowest and Tg (Highest TFN Value) has the highest significance with the help of Tab. 3. However, the evaluation in between Ti and $\mathrm{T} j$ is as $\mathrm{T} 0 \leq \mathrm{T} i \leq \mathrm{T} j \leq \mathrm{Tg}$. The calculated weighted average (OWA) for $\mathrm{n}$ factor is computed via Eq. (1):

$\operatorname{OWA}\left(a_{1}, a_{2}, \ldots a_{n}\right)=\sum_{j=1}^{n} W_{j} b_{j}$

Where, $W=\left(w_{1}, w_{2}, \ldots w_{n}\right)^{S}$ is the vector identified for weighting from rule $\sum_{i=1}^{n} W=1$ and $b_{j}$ defines the higher equivalent of $a_{1}, a_{2}, \ldots \ldots a_{n}$. Thereafter, for calculating these equations, the trapezoidal number $\tilde{C}=(a, b, c, d)$ is computed with the help of Eq. (2)-(5).

$a=\min \left\{a_{L}^{i}, a_{M}^{i}, a_{M}^{i+1}, \ldots \ldots a_{M}^{j}, a_{R}^{j}\right\}=a_{L}^{i}$

$d=\max \left\{a_{L}^{i}, a_{M}^{i}, a_{M}^{i+1}, \ldots \ldots a_{M}^{j}, a_{R}^{j}\right\}=a_{R}^{j}$

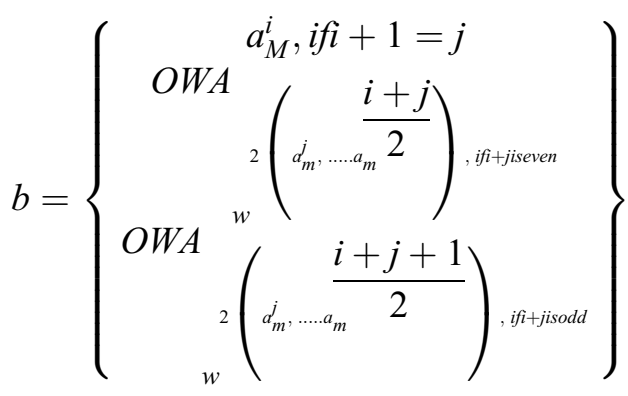

$c=\left\{\begin{array}{c}a_{M}^{i+1}, i f i+1=j \\ \text { OWA }\left(\begin{array}{c}\left.\frac{(i+j)}{2}\right) \\ a_{m}^{j} d_{m}^{j-1}, \ldots \ldots a_{m}\end{array}\right), i f i j \text { isseven } \\ \text { OWA }{ }_{w}^{w}\left(\begin{array}{c}(i+j+1) \\ 2\end{array}\right), i f i+j i s o d d\end{array}\right\}$

After these calculations, the examiners need to identify the 1st and 2nd type weights through $\eta$, as well as identify the number [0,1] via Eqs. (6) and (7). For calculating 1st type weight and 2nd type weight:

$w_{1}^{1}=\eta_{2}, w_{2}^{1}=\eta_{2}\left(1-\eta_{2}\right), \ldots \ldots w_{n}^{1} \eta_{2}\left(1-\eta_{2}\right)^{n-2}$

$w_{1}^{2}=\eta_{1}^{n-1}, w_{2}^{2}=\left(1-\eta_{1}\right) \eta_{1}^{n-1}$

Where $\eta_{1}=\frac{g-(j-1)}{g-1}, \eta_{2}=\frac{g-(j-1)}{g-1}$ and $\mathrm{g}$ denotes the higher rank.

Step 4: The pair-wise comparison matrix $(\tilde{A})$ is completed with the help of Eqs. (8) and (9).

$\tilde{A}=\left[\begin{array}{ccc}1 & \cdots & \tilde{c}_{1 n} \\ \vdots & \ddots & \vdots \\ \tilde{c}_{n 1} & \cdots & 1\end{array}\right]$ 
$\tilde{c}_{j i}=\left(\frac{1}{c i j_{u}}, \frac{1}{c i j_{m 2}}, \frac{1}{c i j_{m 1}}, \frac{1}{c i j_{1}}\right)$

Step 5: To achieve crisp numbers from trapezoidal numbers, the examiners used Eq. (10) that is used for defuzzify.

$\mu_{x}=\frac{l+2 m_{1}+2 m_{2}+h}{6}$

Thereafter, the CR (Consistency Ratio) value is evaluated through Eqs. (11) and (12).

$C I=\frac{\gamma_{\max }-n}{n-1}$

$C R=\frac{C I}{R I}$

In Eqs. (11) and (12), the CI and $\gamma$ max illustrate the consistency index and highest eigenvector of matrix. Furthermore, $\mathrm{n}$ is factor number where assessment is ongoing and RI represents the random index value.

Step 6: The geometric mean for every row is evaluated with Eq. (13).

$\tilde{r}_{i}=\left(\tilde{c}_{i 1} \otimes \tilde{c}_{i 2} \ldots \ldots \otimes \tilde{c}_{i n}\right)^{1 / n}$

Step 7: The weights for highest factor or characteristics (In our $\mathrm{c}$ as, the preventive drugs) are evaluated through Eq. (14).

$\tilde{w}_{i}=\tilde{r}_{1} \otimes\left(\tilde{r}_{1} \oplus \tilde{r}_{2} \ldots \ldots \tilde{r}_{n}\right)^{-1}$

Step 8: All the fuzzy values of matrix are defuzzified through Eq. (15).

$\mu_{x}=\frac{l+2 m_{1}+2 m_{2}+h}{6}$

Step 9: After identifying the defuzzified values, the normalized values are calculated through Eq. (16).

$\frac{\tilde{w}_{i}}{\sum_{i} \sum_{j} \tilde{w}_{j}}$

Now, after step 9 there is a need to select and find appropriate and best alternative through HFLTSTOPSIS approach. TOPSIS methodology is one of the finest and simple approaches to choose and find significant alternatives for real-world problems [38] such as the issue being discussed in this study. TOPSIS methodology provides results that are farthest from the negative perspective in alternatives and nearest from positive alternatives. Further, for this preventive drug evaluation study, methodology used to measure the distance in-between $\mathrm{H} 1 \mathrm{~s}(\operatorname{env}(\mathrm{H} 1 \mathrm{~s})=[\mathrm{Tp}, \mathrm{Tq}])$ and $\mathrm{H} 2 \mathrm{~s}\left(\operatorname{env}(H 2 s)=\left[T_{p}^{*}, T_{q}^{*}\right]\right)$, as shown in Eq. (17).

$d(H 1 s, H 2 s)=\left|q^{*}-q\right|+\left|p^{*}-p\right|$

The other important steps are defined as follows:

Step 10: As a first step in alternative evaluation, let's assume that the prioritized values has $\mathrm{E}$ alternatives $\left(C=\left\{C_{1}, C_{2}, \ldots \ldots C_{E}\right\}\right)$ as well as $\mathrm{n}$ criteria. The practitioners are defined as $e_{x}$ and decision makers are illustrated via K. Further, fuzzy decision matrix is displayed as $\tilde{X}^{l}=\left[H_{S_{i j}}^{l}\right]_{E \times n}$ and the scale for 
HFLTS-TOPSIS is as: Let Scale $=$ \{nothing, very bad, bad, medium, good, very good, and perfect $\}$. Now take two practitioners e1 and e2 to give ranks to two alternatives A1 and A2.

$r_{1}^{1}=$ between medium and good (bt M and $\left.\mathrm{G}\right)$

$r_{2}^{1}=$ at most medium (am M)

$r_{1}^{2}=$ at least $\operatorname{good}(\mathrm{al} \mathrm{G})$

$r_{2}^{2}=$ between very bad and medium (bt VB and M)

The calculation of fuzzy function envelop for intake ranks is defined as follows:

$e n v_{F}(\mathrm{EGH}(\mathrm{btM}$ and $\mathrm{G}))=\mathrm{T}(0.3300,0.5000,0.6700,0.8300)$

$e n v_{F}(\mathrm{EGH}(\mathrm{amM}))=\mathrm{T}(0.0000,0.0000,0.3500,0.6700)$

$\operatorname{env}_{F}(\mathrm{EGH}(\mathrm{alG}))=\mathrm{T}(0.5000,0.8500,1.0000,1.0000)$

$\operatorname{env}_{F}(\mathrm{EGH}(\mathrm{btVB}$ and $\mathrm{M}))=\mathrm{T}(0.0000,0.3000,0.3700,0.6700)$

Step 11: For the second step of assessment, we constructed an aggregated decision matrix $\mathrm{X}=$ [xij] where, $\mathrm{Xij}$ is $\mathrm{xij}=[\mathrm{Tp} \mathrm{ij}$, Tqij] such as Eq. (18).

$T_{p i j}=\min \left\{\min _{i=1}^{K}\left(\max _{t_{i j}}^{x}\right), \max _{i=1}^{K}\left(\min _{t_{i j}}^{x}\right)\right\}$

$T_{q i j}=\max \left\{\min _{i=1}^{K}\left(\max _{t_{i j}}^{x}\right), \max _{i=1}^{K}\left(\min H_{t_{i j}}^{x}\right)\right\}$

Step 12: Let us assume that the Hesitant Fuzzy Linguistic Term Sets (HFLTS) positive perspectives displayed with $\tilde{C}^{+}=\left(\tilde{V}_{1}^{+}, \tilde{V}_{2}^{+}, \ldots \tilde{V}_{n}^{+}\right)$here, $\tilde{V}_{j}^{+}=\left[V_{p j}^{+}, V_{q j}^{+}\right](j=1,2,3 \ldots n)$. Similarly, the negative HFLTS solution of alternatives are displayed as $\tilde{C}^{-}=\left(\tilde{V}_{1}^{-}, \tilde{V}_{2}^{-}, \ldots \tilde{V}_{n}^{-}\right) \quad$ where, $\tilde{V}_{j}^{-}=\left[V_{p j}^{-}, V_{q j}^{-}\right](j=1,2,3 \ldots n)$ now further calculation is defined as following Eqs. (19)-(22).

$\tilde{V}_{p j}^{+}=\max _{i=1}^{K}\left(\max _{i}\left(\min _{S_{i j}}^{x}\right)\right) j \in \alpha_{b}$

and

$\left.\min _{i=1}^{K}\left(\min _{i}\left(\min _{S_{i j}}^{x}\right)\right) j \in \alpha_{c}\right)$

$\tilde{V}_{q j}^{+}=\max _{i=1}^{K}\left(\max _{i}\left(\min _{S_{i j}}^{x}\right)\right) j \in \alpha_{b}$

and

$\left.\min _{i=1}^{K}\left(\min _{i}\left(\min _{S_{i j}}^{x}\right)\right) j \in \alpha_{c}\right)$

$\tilde{V}_{p j}^{-}=\max _{i=1}^{K}\left(\max _{i}\left(\min _{S_{i j}}^{x}\right)\right) j \in \alpha_{c}$

and

$\left.\min _{i=1}^{K}\left(\min _{i}\left(\min _{S_{i j}}^{x}\right)\right) j \in \alpha_{b}\right)$ 
$\tilde{V}_{q j}^{-}=\max _{i=1}^{K}\left(\max _{i}\left(\min _{S_{i j}}^{x}\right)\right) j \in \alpha_{c}$

and

$\left.\min _{i=1}^{K}\left(\min _{i}\left(\min _{S_{i j}}^{x}\right)\right) j \in \alpha_{b}\right)$

Step 13: Now, the positive and negative ideal separation matrix $\left(D^{+}\right.$and $\left.D^{-}\right)$through Eqs. (23) and (24) are assessed.

$D^{+}=\left[\begin{array}{lll}d\left(x_{11}, \tilde{V}_{1}^{+}\right)+ & d\left(x_{12}, \tilde{V}_{2}^{+}\right)+ & \ldots+d\left(x_{1 n}, \tilde{V}_{n}^{+}\right) \\ d\left(x_{21}, \tilde{V}_{1}^{+}\right)+ & d\left(x_{22}, \tilde{V}_{2}^{+}\right)+ & \ldots+d\left(x_{21}, \tilde{V}_{n}^{+}\right) \\ d\left(x_{m 1}, \tilde{V}_{1}^{+}\right)+ & d\left(x_{m 2}, \tilde{V}_{1}^{+}\right)+ & \ldots+d\left(x_{m n}, \tilde{V}_{n}^{+}\right)\end{array}\right]$
$D^{-}=\left[\begin{array}{lll}d\left(x_{11}, \tilde{V}_{1}^{-}\right)+ & d\left(x_{12}, \tilde{V}_{2}^{-}\right)+ & \ldots+d\left(x_{1 n}, \tilde{V}_{n}^{-}\right) \\ d\left(x_{21}, \tilde{V}_{1}^{-}\right)+ & d\left(x_{22}, \tilde{V}_{2}^{-}\right)+ & \ldots+d\left(x_{21}, \tilde{V}_{n}^{-}\right) \\ d\left(x_{m 1}, \tilde{V}_{1}^{-}\right)+ & d\left(x_{m 2}, \tilde{V}_{1}^{-}\right)+ & \ldots+d\left(x_{m n}, \tilde{V}_{n}^{-}\right)\end{array}\right]$

Step 14: After computing the D+ and D- values, the closeness score is calculated for them by following Eqs. (25) and (26).

$C S\left(A_{i}\right)=\frac{D_{i}^{+}}{D_{i}^{+}+D_{i}^{-}}, i=1,2, \ldots m$

Here,

$D_{i}^{+}=\sum_{j=1}^{n} d\left(x_{i j}, V_{j}^{+}\right)$and $D_{i}^{-}=\sum_{j=1}^{n} d\left(x_{i j}, V_{j}^{-}\right)$

Step 15: Calculation of the closeness values for every alternative creates an order of them based on closeness value for clear and understandable form. Additionally, the actual assessment and numerical analysis of Fig. 1 are described in the following section with appropriate tables. Sanjay Gandhi Postgraduate Institute of Medical Sciences (SGPGI), Lucknow has been taken as alternatives in this study for evaluation and the results have been calculated by using HFLTS-AHP-TOPSIS methodology.

\section{Numerical Analysis and Results}

To facilitate the adopted and discussed HFLTS-AHP-TOPSIS methodology in our context, the authors took opinions and data for each of the drugs mentioned above from hundred experts and practitioners all around from the healthcare sector. The experts are invited in an online meeting app and informed about the hierarchy model for the drugs in use of treating COVID-19. The experts' views are collected in the form of linguistic values and the calculations are done on them, as already illustrated in the previous section. The experts' data is also referred to for constructing the pair-wise comparison matrix. The experts also agreed to develop a fuzzy envelope for level 1 of hierarchy where two paths of treatment are categorized by authors. The developed fuzzy envelope values for the 1st level of the hierarchy have been described.

The evaluation process for level 1 of the hierarchy is conducted with the help of Eqs. (1)-(9). With the available scores, the CR value is calculated and t is verified through step 5 and Eqs. (10)-(12). Further, Eqs. (13) and (14) is used to evaluate the fuzzy weights for level 1 and then through Eq. (14) other fuzzy weights for level 2 of hierarchy is assessed by authors. After that, defuzzified value of associated drugs is evaluated via Eqs. (15) and (16) is used by authors to create normalized values for estimated defuzzified value. Tab. 4 
illustrates the different ranks as well as their associated weights for every selected and evaluated course of treatment for SARS-CoV-2.

Table 4: Global weights through the hierarchy

\begin{tabular}{|c|c|c|c|c|c|c|c|}
\hline $\begin{array}{l}\text { Criteria of } \\
\text { Level } 1\end{array}$ & $\begin{array}{l}\text { Local Weights of } \\
\text { Level } 1\end{array}$ & Criteria of Level 2 & $\begin{array}{l}\text { Local Weights of } \\
\text { Level } 2\end{array}$ & $\begin{array}{l}\text { Global Weights of } \\
\text { Level } 2\end{array}$ & $\begin{array}{l}\text { Defuzzified } \\
\text { Weights }\end{array}$ & $\begin{array}{l}\text { Normalized } \\
\text { Weights }\end{array}$ & Ranks \\
\hline \multirow[t]{8}{*}{$\begin{array}{l}\text { Allopath } \\
\text { [C1] }\end{array}$} & \multirow[t]{8}{*}{$\begin{array}{l}0.3317,0.3782 \\
0.4472,0.5745\end{array}$} & Remdesivir [C11] & $\begin{array}{l}0.0500,0.1600 \\
0.2800,1.0100\end{array}$ & $\begin{array}{l}0.0166,0.0605 \\
0.1252,0.5801\end{array}$ & 0.16136 & 0.06219 & 12 \\
\hline & & $\begin{array}{l}\text { Lopinavir/Ritonavir } \\
\text { [C12] }\end{array}$ & $\begin{array}{l}0.0580,0.1310 \\
0.2400,0.4510\end{array}$ & $\begin{array}{l}0.0050,0.0219 \\
0.1264,0.8881\end{array}$ & 0.16270 & 0.06272 & 9 \\
\hline & & $\begin{array}{l}\text { HCQ and } \\
\text { Azithromycin [C13] }\end{array}$ & $\begin{array}{l}0.0920,0.1800 \\
0.3340,0.6990\end{array}$ & $\begin{array}{l}0.0011,0.0060 \\
0.0295,0.2312\end{array}$ & 0.21120 & 0.08140 & 5 \\
\hline & & $\begin{array}{l}\text { Convalescent } \\
\text { plasma [C14] }\end{array}$ & $\begin{array}{l}0.0470,0.1370 \\
0.2540,0.3550\end{array}$ & $\begin{array}{l}0.0012,0.0088 \\
0.0473,0.2236\end{array}$ & 0.13960 & 0.05381 & 13 \\
\hline & & $\begin{array}{l}\text { High-dose IVIg } \\
\text { [C15] }\end{array}$ & $\begin{array}{l}0.0310,0.0640 \\
0.1290,0.2700\end{array}$ & $\begin{array}{l}0.0050,0.0219 \\
0.1264,0.8881\end{array}$ & 0.19340 & 0.07454 & 8 \\
\hline & & Tocilizumab [C16] & $\begin{array}{l}0.0580,0.1310 \\
0.2400,0.4510\end{array}$ & $\begin{array}{l}0.0012,0.0088 \\
0.0473,0.2236\end{array}$ & 0.29230 & 0.11266 & 2 \\
\hline & & Siltuximab [C17] & $\begin{array}{l}0.1410,0.2910 \\
0.3710,0.6870\end{array}$ & $\begin{array}{l}0.0020,0.0128 \\
0.0473,0.3227\end{array}$ & 0.16220 & 0.06252 & 11 \\
\hline & & $\begin{array}{l}\text { Mesenchymal Stem } \\
\text { Cell }[\mathrm{C} 18]\end{array}$ & $\begin{array}{l}0.0390,0.0990 \\
0.1830,0.4510\end{array}$ & $\begin{array}{l}0.0010,0.0061, \\
0.0675,0.3116\end{array}$ & 0.21150 & 0.08152 & 3 \\
\hline \multirow[t]{5}{*}{$\begin{array}{l}\text { Ayurveda } \\
{[\mathrm{C} 2]}\end{array}$} & \multirow[t]{5}{*}{$\begin{array}{l}0.1400,0.2400 \\
0.6400,0.6900\end{array}$} & Ashwagandha [C21] & $\begin{array}{l}0.2040,0.2910 \\
0.5350,1.0000\end{array}$ & $\begin{array}{l}0.0050,0.0219 \\
0.1264,0.8881\end{array}$ & 0.19990 & 0.07705 & 6 \\
\hline & & Guduchi [C22] & $\begin{array}{l}0.1210,0.2370 \\
0.5000,1.0000\end{array}$ & $\begin{array}{l}0.0004,0.0031 \\
0.0171,0.1173\end{array}$ & 0.19350 & 0.07458 & 7 \\
\hline & & Yashtimadhu [C23] & $\begin{array}{l}0.0790,0.1980 \\
0.2450,0.7440\end{array}$ & $\begin{array}{l}0.0109,0.0471 \\
0.1556,0.1693\end{array}$ & 0.29260 & 0.11278 & 1 \\
\hline & & Peepli [C24] & $\begin{array}{l}0.0390,0.0990 \\
0.1830,0.4510\end{array}$ & $\begin{array}{l}0.0020,0.0128 \\
0.0473,0.3227\end{array}$ & 0.16270 & 0.06271 & 10 \\
\hline & & Ayush-64 [C25] & $\begin{array}{l}0.0490,0.1450, \\
0.1940,0.4810\end{array}$ & $\begin{array}{l}0.0068,0.0345 \\
0.1232,0.3324\end{array}$ & 0.21150 & 0.08151 & 4 \\
\hline
\end{tabular}

Results related to HFLTS-AHP for ranking assessment shows that Convalescent Plasma [C14] from Allopathy [C1] gets the highest priority and rank (Rank = 13), whereas Yashtimadhu [C23] from Ayurveda [C2] is ranked the lowest at number 1. After obtaining the results from HFLTS-AHP methodology, we applied the HFLTS-TOPSIS methodology on 5 different hospitals as alternatives to test the obtained results from HFLTS-AHP method. Further, to test the obtained results in Tab. 4, Eqs. (17)(26) are used. The technical data of all 5 alternatives has been displayed in Tab. 5 with the help of Step 10 and Eqs. (17) and (18). In addition, with the help of Eqs. (19)-(22), outcomes of normalized fuzzy matrix and weighted normalized fuzzy matrix are calculated. At last, we evaluated the closeness coefficients of alternatives through Eqs. (23)-(26) as shown in Tab. 6.

Tab. 6 describes the satisfaction degree for 5 different selected alternatives; Alternative A1 denotes good performance and Alternative A2 publishes poor performance with respect to the effectiveness of the selected drugs. Therefore, it is clearly evident that alternative A1 has the best performance ratio among all the other alternatives. Further, if we look beyond the satisfaction degree for various alternatives, then it is evident that there is not so much fluctuation in the results, except for the alternative A2. This is also an ideal situation and effective result validation from a layman perspective. 
Table 5: Subjective cognition outcomes of evaluators in linguistic terms

\begin{tabular}{|c|c|c|c|c|c|}
\hline Criteria/Alternatives & A1 & $\mathrm{A} 2$ & A3 & A4 & A5 \\
\hline Remdesivir [C11] & $\begin{array}{l}1.4500,3.1800 \\
5.1800,6.2500\end{array}$ & $\begin{array}{l}1.5500,3.1800 \\
5.1800,6.5400\end{array}$ & $\begin{array}{l}1.4500,3.1800 \\
5.1800,6.2500\end{array}$ & $\begin{array}{l}1.5500,3.1800 \\
5.1800,6.5400\end{array}$ & $\begin{array}{l}1.4500,3.1800 \\
5.1800,6.2500\end{array}$ \\
\hline $\begin{array}{l}\text { Lopinavir/Ritonavir } \\
\text { [C12] }\end{array}$ & $\begin{array}{l}1.9100,3.7300, \\
5.7300,7.5100\end{array}$ & $\begin{array}{l}2.8200,4.6400 \\
6.6400,8.5100\end{array}$ & $\begin{array}{l}1.9100,3.7300, \\
5.7300,7.5100\end{array}$ & $\begin{array}{l}2.8200,4.6400 \\
6.6400,8.5100\end{array}$ & $\begin{array}{l}1.9100,3.7300, \\
5.7300,7.5100\end{array}$ \\
\hline $\begin{array}{l}\text { HCQ and } \\
\text { Azithromycin [C13] }\end{array}$ & $\begin{array}{l}1.6400,3.5500 \\
5.5500,6.7300\end{array}$ & $\begin{array}{l}1.8200,3.7300 \\
5.7300,6.7300\end{array}$ & $\begin{array}{l}1.6400,3.5500, \\
5.5500,6.7300\end{array}$ & $\begin{array}{l}1.8200,3.7300 \\
5.7300,6.7300\end{array}$ & $\begin{array}{l}1.6400,3.5500, \\
5.5500,6.7300\end{array}$ \\
\hline $\begin{array}{l}\text { Convalescent } \\
\text { Plasma }[\mathrm{C} 14]\end{array}$ & $\begin{array}{l}2.4500,4.2700, \\
6.2700,8.6500\end{array}$ & $\begin{array}{l}0.9100,2.4500 \\
4.4500,5.6500\end{array}$ & $\begin{array}{l}2.4500,4.2700, \\
6.2700,8.6500\end{array}$ & $\begin{array}{l}0.9100,2.4500 \\
4.4500,5.6500\end{array}$ & $\begin{array}{l}2.4500,4.2700, \\
6.2700,8.6500\end{array}$ \\
\hline $\begin{array}{l}\text { High-dose IVIg } \\
{[\text { C15] }}\end{array}$ & $\begin{array}{l}1.9100,3.7300 \\
5.7300,7.5100\end{array}$ & $\begin{array}{l}2.8200,4.6400 \\
6.6400,8.5100\end{array}$ & $\begin{array}{l}1.9100,3.7300, \\
5.7300,7.5100\end{array}$ & $\begin{array}{l}2.8200,4.6400 \\
6.6400,8.5100\end{array}$ & $\begin{array}{l}1.9100,3.7300 \\
5.7300,7.5100\end{array}$ \\
\hline Tocilizumab [C16] & $\begin{array}{l}0.8200,2.2700, \\
4.2700,6.6500\end{array}$ & $\begin{array}{l}1.4500,3.0700, \\
4.9100,5.6500\end{array}$ & $\begin{array}{l}0.8200,2.2700, \\
4.2700,6.6500\end{array}$ & $\begin{array}{l}1.4500,3.0700 \\
4.9100,5.6500\end{array}$ & $\begin{array}{l}0.8200,2.2700, \\
4.2700,6.6500\end{array}$ \\
\hline Siltuximab [C17] & $\begin{array}{l}1.6400,3.5500 \\
5.5500,6.7300\end{array}$ & $\begin{array}{l}1.8200,3.7300 \\
5.7300,6.7300\end{array}$ & $\begin{array}{l}1.6400,3.5500, \\
5.5500,6.7300\end{array}$ & $\begin{array}{l}1.8200,3.7300 \\
5.7300,6.7300\end{array}$ & $\begin{array}{l}1.6400,3.5500, \\
5.5500,6.7300\end{array}$ \\
\hline $\begin{array}{l}\text { Mesenchymal Stem } \\
\text { Cell [C18] }\end{array}$ & $\begin{array}{l}2.5500,4.4500 \\
6.4500,7.8400\end{array}$ & $\begin{array}{l}2.8200,4.6400 \\
6.6400,6.6400\end{array}$ & $\begin{array}{l}2.5500,4.4500, \\
6.4500,7.8400\end{array}$ & $\begin{array}{l}2.8200,4.6400 \\
6.6400,6.6400\end{array}$ & $\begin{array}{l}2.5500,4.4500 \\
6.4500,7.8400\end{array}$ \\
\hline Ashwagandha [C21] & $\begin{array}{l}1.4500,3.1800 \\
5.1800,6.2500\end{array}$ & $\begin{array}{l}1.5500,3.1800 \\
5.1800,6.5400\end{array}$ & $\begin{array}{l}1.4500,3.1800 \\
5.1800,6.2500\end{array}$ & $\begin{array}{l}1.5500,3.1800 \\
5.1800,6.5400\end{array}$ & $\begin{array}{l}1.4500,3.1800 \\
5.1800,6.2500\end{array}$ \\
\hline Guduchi [C22] & $\begin{array}{l}1.9100,3.7300 \\
5.7300,7.5100\end{array}$ & $\begin{array}{l}2.8200,4.6400 \\
6.6400,8.5100\end{array}$ & $\begin{array}{l}1.9100,3.7300, \\
5.7300,7.5100\end{array}$ & $\begin{array}{l}2.8200,4.6400 \\
6.6400,8.5100\end{array}$ & $\begin{array}{l}1.9100,3.7300, \\
5.7300,7.5100\end{array}$ \\
\hline Yashtimadhu [C23] & $\begin{array}{l}1.6400,3.5500 \\
5.5500,6.7300\end{array}$ & $\begin{array}{l}1.8200,3.7300 \\
5.7300,6.7300\end{array}$ & $\begin{array}{l}1.6400,3.5500 \\
5.5500,6.7300\end{array}$ & $\begin{array}{l}1.8200,3.7300 \\
5.7300,6.7300\end{array}$ & $\begin{array}{l}1.6400,3.5500 \\
5.5500,6.7300\end{array}$ \\
\hline Peepli [C24] & $\begin{array}{l}2.4500,4.2700, \\
6.2700,8.6500\end{array}$ & $\begin{array}{l}0.9100,2.4500 \\
4.4500,5.6500\end{array}$ & $\begin{array}{l}2.4500,4.2700, \\
6.2700,8.6500\end{array}$ & $\begin{array}{l}0.9100,2.4500 \\
4.4500,5.6500\end{array}$ & $\begin{array}{l}2.4500,4.2700, \\
6.2700,8.6500\end{array}$ \\
\hline Ayush-64 [C25] & $\begin{array}{l}1.9100,3.7300, \\
5.7300,7.5100\end{array}$ & $\begin{array}{l}2.8200,4.6400 \\
6.6400,8.5100\end{array}$ & $\begin{array}{l}1.9100,3.7300, \\
5.7300,7.5100\end{array}$ & $\begin{array}{l}2.8200,4.6400 \\
6.6400,8.5100\end{array}$ & $\begin{array}{l}1.9100,3.7300, \\
5.7300,7.5100\end{array}$ \\
\hline
\end{tabular}

Table 6: Closeness coefficients among different alternatives

\begin{tabular}{lllll}
\hline Alternatives & $\mathrm{d}+\mathrm{i}$ & $\mathrm{d}-\mathrm{i}$ & Gap Degree of CC $+\mathrm{i}$ & Satisfaction Degree of CC-i \\
\hline A1 & 0.0435649 & 0.0245742 & 0.378457 & 0.6345764 \\
A2 & 0.0346754 & 0.0464578 & 0.644579 & 0.3645784 \\
A3 & 0.0434579 & 0.0245781 & 0.386457 & 0.6124357 \\
A4 & 0.0324574 & 0.0445167 & 0.512457 & 0.4546751 \\
A5 & 0.0345784 & 0.0445127 & 0.524576 & 0.4457444 \\
\hline
\end{tabular}

\section{Discussion}

COVID-19 pandemic is one of the most harmful outbreaks of the century. As cited in the material and method section of this study, the infected COVID-19 patients' ratio is increasing at a worrying pace in every region of the globe. According to the analysis of the material and method section of this paper, it is evident that the death ratio of disease is much lower in the comparison of infection ratio. As yet, no standardized and 
officially declared treatment [1] for the SARS-CoV-2 is available but the doctors are treating patients according to the symptomatic medication process [2]. In this scenario, the need of the hour is to find an appropriate pathway for selecting and prioritizing an effective course of treatment for Coronavirus that would help the medical staff to tackle this acute crisis expeditiously. Hence, the analysis and categorization of different scientifically proven and recommended courses of treatment that are being used to cure COVID-19 cases based on their effectivity levels has become imperative and this is the only main objective of this article.

To meet the objectives of this study, the authors conducted the evaluation of various therapies being prescribed by the doctors treating COVID-19 cases. The obtained results show that "Convalescent Plasma" is the most preferred course for treatment against the Coronavirus according to the evaluation process. Yashtimadhu has the lowest rank in the calculation and on the basis of that, we can say it is least efficacious in the management of COVID-19 patients. This type of assessment provides a reliable and a conclusive reference for the doctors who might wish to corroborate the efficacy of various courses of treatment being pursued across the globe for COVID-19. The estimates of our study would also add to the scientific community's R\&D efforts for containing the COVID contagion.

Additionally, when a mathematical assessment is conducted, it is important to understand and analyze the robustness of the evaluated results [39]. In order to estimate the quality of calculated results, we performed a threat to validity or robustness analysis of assessed results where the data for one alternative at a time shifts by 0.05 , and for the other alternatives, the weights are constant. It must be clarified here that the selection of the best alternative in evaluation is not affected by changes in values. Tab. 7 shows the sensitivity analysis results in tabular form. If we analyze and view the obtained results from robustness analysis, then it is evident that the variation in between the effectiveness of the various courses of treatments for the SARS-CoV-2 is negligible. This proves that the quality or robustness of the result is effectively good.

Table 7: Sensitivity analysis

\begin{tabular}{|c|c|c|c|c|c|c|}
\hline Tryouts & & A1 & $\mathrm{A} 2$ & A3 & A4 & A5 \\
\hline Tryout- 0 & Satisfaction Degree (CC-i) & 0.6345764 & 0.3645784 & 0.6124357 & 0.4546751 & 0.4457751 \\
\hline Tryout-1 & & 0.6699784 & 0.5545357 & 0.5232751 & 0.6202751 & 0.5085751 \\
\hline Tryout-2 & & 0.6742357 & 0.5615784 & 0.5137751 & 0.6859784 & 0.5050357 \\
\hline Tryout-3 & & 0.7292357 & 0.6020751 & 0.5532751 & 0.6589357 & 0.5460784 \\
\hline Tryout-4 & & 0.5908751 & 0.4821784 & 0.4482751 & 0.6065784 & 0.4291784 \\
\hline Tryout-5 & & 0.5908784 & 0.4855751 & 0.4407764 & 0.5364751 & 0.4290357 \\
\hline Tryout-6 & & 0.6740357 & 0.5651357 & 0.5260751 & 0.6121764 & 0.5079764 \\
\hline Tryout-7 & & 0.6295764 & 0.5272751 & 0.4810784 & 0.5625764 & 0.4661357 \\
\hline Tryout- 8 & & 0.6250751 & 0.5311357 & 0.4764751 & 0.5482357 & 0.4659764 \\
\hline Tryout-9 & & 0.6449751 & 0.5155764 & 0.4832784 & 0.5769764 & 0.4592357 \\
\hline Tryout-10 & & 0.6432784 & 0.5265357 & 0.4847357 & 0.5755357 & 0.4629751 \\
\hline Tryout-11 & & 0.6272751 & 0.5025764 & 0.4862764 & 0.5735764 & 0.4702764 \\
\hline Tryout-12 & & 0.6196751 & 0.4975357 & 0.4870357 & 0.5725751 & 0.4735751 \\
\hline Tryout-13 & & 0.7072784 & 0.7480784 & 0.5647764 & 0.6712751 & 0.5545784 \\
\hline
\end{tabular}


In the Tab. 7 above, the results are describing that the variation of 0.05 shift in values for the alternatives is negligible; the linear values for every alternative is shown in the Tab. 7. Further, the Tab. 7 also displays that variation in values does not affect the estimated results from the methodology. In a nutshell, it is evident that the quality of evaluated results in this study is good and effective in any situation and changes.

Furthermore, the evaluated results are related to a highly sensitive domain (treatment) due to that authors wanted to test the results one more time for verifying their accuracy. To achieve this goal, we performed a Marginal Mean analysis of the obtained results from the original results in Tab. 6 and results of sensitivity analysis in Tab. 7. Marginal Mean analysis is a simple however effective mathematical process that provides a precise view of the results [40]. Marginal mean is a concept that is basically used to statistically portray data in large scale data sets. In our context, we determined the marginal mean for every tryout performed for sensitivity analysis along with original tested results to identify the actual fluctuation, if any, in values when factor's weight slightly differ from the previous readings.

Moreover after identifying the marginal means for every tryout and original tested results (displayed in Tab. 8), authors concluded that the highest difference in between original evaluated results marginal mean and various tryout's marginal mean is only of 0.14 , that is $(<0.20)$, and hence, considered negligible. Thus, it is evident that the obtained results from the adopted methodology are in good quality and have a low sensitivity that means the efficiency and effectiveness of evaluated results are high.

Table 8: Marginal mean evaluation

\begin{tabular}{lllllll}
\hline Experiments/Alternatives & A1 & A2 & A3 & A4 & A5 & Marginal Mean \\
\hline Original Results & 0.6345764 & 0.3645784 & 0.6124357 & 0.4546751 & 0.4457444 & 0.502402 \\
Tryout-0 & 0.6345764 & 0.3645784 & 0.6124357 & 0.4546751 & 0.4457751 & 0.502408 \\
Tryout-1 & 0.6699784 & 0.5545357 & 0.5232751 & 0.6202751 & 0.5085751 & 0.575327 \\
Tryout-2 & 0.6742357 & 0.5615784 & 0.5137751 & 0.6859784 & 0.5050357 & 0.588120 \\
Tryout-3 & 0.7292357 & 0.6020751 & 0.5532751 & 0.6589357 & 0.5460784 & 0.617920 \\
Tryout-4 & 0.5908751 & 0.4821784 & 0.4482751 & 0.6065784 & 0.4291784 & 0.511417 \\
Tryout-5 & 0.5908784 & 0.4855751 & 0.4407764 & 0.5364751 & 0.4290357 & 0.496548 \\
Tryout-6 & 0.6740357 & 0.5651357 & 0.5260751 & 0.6121764 & 0.5079764 & 0.577079 \\
Tryout-7 & 0.6295764 & 0.5272751 & 0.4810784 & 0.5625764 & 0.4661357 & 0.533328 \\
Tryout-8 & 0.6250751 & 0.5311357 & 0.4764751 & 0.5482357 & 0.4659764 & 0.529379 \\
Tryout-9 & 0.6449751 & 0.5155764 & 0.4832784 & 0.5769764 & 0.4592357 & 0.536008 \\
Tryout-10 & 0.6432784 & 0.5265357 & 0.4847357 & 0.5755357 & 0.4629751 & 0.538612 \\
Tryout-11 & 0.6272751 & 0.5025764 & 0.4862764 & 0.5735764 & 0.4702764 & 0.531996 \\
Tryout-12 & 0.6196751 & 0.4975357 & 0.4870357 & 0.5725751 & 0.4735751 & 0.530079 \\
Tryout-13 & 0.7072784 & 0.7480784 & 0.5647764 & 0.6712751 & 0.5545784 & 0.649197 \\
Marginal Mean & 0.646368 & 0.521930 & 0.512932 & 0.580701 & 0.478010 & \\
\hline
\end{tabular}

Furthermore, to reiterate on the choice of the adopted methodology and establish it's appropriateness as well as benefits for the present study, we conducted a comparative analysis from other similar MCDM techniques. The obtained results from the comparative analysis are described and illustrated in the following Tab. 9. 
Table 9: Comparative analysis

\begin{tabular}{llllll}
\hline $\begin{array}{l}\text { Different MCDM Approaches/ } \\
\text { Alternatives }\end{array}$ & A1 & A2 & A3 & A4 & A5 \\
\hline HFLTS-AHP-TOPSIS & 0.6345764 & 0.3645784 & 0.6124357 & 0.4546751 & 0.4457444 \\
Fuzzy-AHP-TOPSIS & 0.6345784 & 0.5375487 & 0.4754674 & 0.5845127 & 0.4784579 \\
Fuzzy-Delphi-AHP-TOPSIS & 0.6275487 & 0.5145794 & 0.4451245 & 0.5645127 & 0.4645784 \\
Classical-AHP-TOPSIS & 0.6245127 & 0.5451427 & 0.4451245 & 0.5451274 & 0.4645794 \\
Delphi-AHP-TOPSIS & 0.6242154 & 0.5145127 & 0.4745124 & 0.5451279 & 0.4645784 \\
\hline
\end{tabular}

HFLTS has often been adopted by researchers in the previous years because the hesitant situation is so common at the time of taking opinions from the experts [41]. HFLTS approach is the process where every associated attribute has some membership value other than fuzzy set values. This type of advancement allows the experts to provide their opinions on the hierarchy to assign weights according to their own preferences without any restriction of the pre-defined numeric assignment. Further, in this comparison analysis authors choose Fuzzy-AHP-TOPSIS, Fuzzy-Delphi-AHP-TOPSIS, Classical-AHP-TOPSIS, and Delphi-AHPTOPSIS. In order to analyze different methodologies for comparison, the same experts are approached to take opinions for different selected methods. Thereafter, the same five alternatives are taken by authors to test the performance of evaluated results from various selected methods. Tab. 9 clearly illustrates that all methods are displaying that Alternative A1 has the best performance ratio in all the five selected alternatives for testing. Moreover, Tab. 9 illustrates that the results obtained by HFLTS-AHP-TOPSIS and Fuzzy-Delphi-AHP-TOPSIS have a linear and continuous value calculation without any sensitive fluctuation. In case of fluctuation in values for different alternatives by other MCDM approaches, we observed some sensitivity in their calculation and evaluated results. Therefore, it is evident that the adopted methodology has an accurate result ratio in comparison to other techniques.

The evaluated results of this study are based on scientific evaluation, unique idea, and systematic categorization. Hence, the study's analysis will be an authentic reference for the research community as well as the doctors and medical experts in simplifying the procedure for medication in COVID-19 besides providing a pathway for future researchers to classify and assess more complex situations like this. The present study's empirical tabulations will be a significant contribution and serve as a cornerstone for advanced medicine research through computational methodologies. The enumeration below summarizes the key contributions of our study:

- The study adopts a scientific methodology and performs a numerical simulation for evaluation to estimate the effectiveness of the various courses of treatments for coronavirus. This type of evaluation is a unique endeavour and will be an accurate repository for doctors who can peruse our tabulations and opt for the most preferred course of treatment for COVID-19 cases.

- With no certified and guaranteed treatment/therapy or vaccine available against SARS-CoV-2, healthcare experts and researchers are mired in confusion at present. Our study is based on 3 elemental steps- (i) identifying the 13 most widely used treatment therapies for COVID-19 treatment and establishing their efficacy through various research investigations involving the therapy of active COVID-19 cases, (ii) Collating doctors' opinions on those drugs, (iii) Conducting a thoroughly conclusive mathematical assessment to determine the most prioritized course of treatment. Hence, scientifically processed and tested results from computational methodology in our study will aid in dispelling the ambivalence around the choice of the efficacious drugs. 
- Results discussed in the paper portray and create a systematic pathway for healthcare experts to choose and select an appropriate course of treatment for SARS-CoV-2 treatment on the basis of numerical prioritization and effectiveness assessment.

- The belief system and logical procedure embraced in this investigation will end up being an achievement for future scientists and can be utilized later on in numerous different fields.

- Additionally, there are numerous other future possibilities that are also associated with this study. As an extension of this study, there is scope to add more treatment paths and courses to cover more patterns of treatment and suggest a large prioritization list based on effectiveness. Moreover, there is a possibility to apply this methodology to rank the most infected or less infected regions after its forecasting for future years. Furthermore, as in the context of adopted methodology in this paper, there is a possibility of maintaining consensus in a valid and appropriate form by selecting the approach of $[45,46]$ studies that can lead the future possibilities into an effective result.

This study does, however, has future opportunities which are listed below:

- The study summarizes and selects only widely used and popular courses of treatments for SARSCoV-2. However, authors believe that there are various other medicines and pattern of treatments for COVID-19 patients which are possibly under use however yet not in the purview of large range of audience.

- The evaluated results in this study are mathematically achieved and evaluated based on medical practitioners' suggestions and opinions only, whereas drugs and medicines are a field where actual characteristics of the element can only provide accurate and efficient results. So, there is a possibility that in some cases and for some expert's opinion, the obtained results are not as convincing as they should be.

- With the help of the evaluated outcomes, future practitioners will make a set of guidelines for managing the impact of epidemics as well as pandemics such as COVID-19 pandemic.

- In future, data collection tool may be changed and other methods that may give more unambiguous results can be estimated.

\section{Conclusions}

A huge and frequent infection ratio clearly portrays the immense need for a SARS-CoV-2 vaccine or a standard treatment pattern. Doctors have been prescribing different courses of therapy as per their assessment of the patients' condition, however, the battle with COVID-19 is far from over. There are a variety of treatment courses being suggested by various medical experts and countries. However, numerous suggestions to treat COVID-19 patients is creating confusion for the doctors and researchers. To address this scientific gap, the study prioritizes the various courses of treatment in the order of preference. More specifically, we selected only the most widely used courses of treatment being prescribed in Allopathy and Ayurveda for our analysis. The evaluation of effectiveness is performed via a scientific MCDM approach called HFLTS-AHP-TOPSIS that provided accurate and good quality results (Tested). Moreover, according to the assessment process, it is evident that Convalescent plasma is the most preferred course with the highest priority, while Yashtimadhu is the least preferred medication with the lowest priority. All the other treatment procedures lie in between this two-courses of treatment ranking. Moreover, to validate the results, the authors performed Sensitivity Analysis, Marginal Mean, and Comparison analysis to analyze the quality and efficiency of the obtained results. Through these analyses, it is clearly verified that assessed results in the study are highly good in quality (through Sensitivity Analysis), efficiently effective (through Marginal Mean assessment), and evaluated as well as assessed through the best possible methodology (through Comparison Analysis). Thus the present study with its' 
verified, accurate, and authentic empirical frame posits a valid premise for reference by the scientific community and the medical fraternity. We strongly believe that the suggested results and priority list (Ranks) of various courses of treatments will be a reliable reference for the medical experts in treating COVID-19 patients.

Acknowledgement: This research was supported by Taif University Researchers Supporting Project number (TURSP-2020/254), Taif University, Taif, Saudi Arabia.

Funding Statement: This Project was funded by the Taif University Researchers Supporting Projects at Taif University, Kingdom of Saudi Arabia, under grant number: TURSP-2020/254.

Conflicts of Interest: The authors declare that they have no conflicts of interest to report regarding the present study.

\section{References}

[1] Mythbusters, Coronavirus Disease (COVID-19) Advice for the Public, World Health Organization: Geneva, Switzerland, 2020. [Online]. Available: https://www.who.int/emergencies/diseases/novel-coronavirus-2019/ advice-for-public/myth-busters/.

[2] T. Dzieciatkowski, L. Szarpak, K. J. Filipiak, M. Jaguszewski, J. R. Ladny et al., "COVID-19 challenge for modern medicine," Cardiology Journal, vol. 27, no. 2, pp. 175-183, 2020.

[3] Lockdown cannot be a Permanent Solution: Kodagu DC, The Hindu:: Mysuru, 2020. [Online]. Available: https://www. thehindu.com/news/national/karnataka/lockdown-cannot-be-a-permanent-solution-kodagu-dc/article32123316.ece/.

[4] R. M. Rodriguez, L. Martinez and F. Herrera, "Hesitant fuzzy linguistic term sets for decision making," IEEE Transactions on Fuzzy Systems, vol. 20, no. 1, pp. 109-119, 2012.

[5] WHO Coronavirus Disease (COVID-19) Dashboard, World Health Organization: Geneva, Switzerland, 2020. [Online]. Available: https://covid19.who.int/.

[6] Regional Offices, Regionals Offices of World Health Organization: Geneva, Switzerland, 2020. [Online]. Available: https://www.who.int/about/who-we-are/regional-offices/.

[7] Z. Zhang, W. Yu, L. Martinez and Y. Gao, "Managing multigranular unbalanced hesitant fuzzy linguistic information in multiattribute large-scale group decision making: A linguistic distribution-based approach," IEEE Transactions on Fuzzy Systems, vol. 28, no. 11, pp. 2875-2889, 2020.

[8] W. Yu, Z. Zhang and Q. Zhong, "Consensus reaching for MAGDM with multi-granular hesitant fuzzy linguistic term sets: A minimum adjustment-based approach," Annals of Operations Research, vol. 45, no. 8, pp. 1-24, 2019.

[9] Z. Zhang, J. Gao, Y. Gao and W. Yu, "Two-sided matching decision making with multi-granular hesitant fuzzy linguistic term sets and incomplete criteria weight information," Expert Systems with Applications, Article on Press, vol. 168, pp. 114311, 2021.

[10] R. C. Chen, C. Y. Huang, C. T. Bau and L. S. Chen, "A decision support system for diabetes medicine selection using patient centered treatment based on fuzzy logic and domain ontology," International Journal of Innovative Computing, Information and Control, vol. 13, no. 5, pp. 1681-1692, 2017.

[11] J. Wang, "Fast identification of possible drug treatment of coronavirus disease-19 (covid-19) through computational drug repurposing study," Journal of Chemical Information and Modeling, vol. 60, no. 6, pp. 3277-3286, 2020.

[12] Z. Ren, H. Liao and Y. Liu, "Generalized Z-numbers with hesitant fuzzy linguistic information and its application to medicine selection for the patients with mild symptoms of the COVID-19," Computers \& Industrial Engineering, vol. 145, no. 2020, pp. 106517, 2020.

[13] S. Devi, M. Kumar, P. K. Upadhyay, A. Malik, B. Kumari et al., "An overview of novel corona virus 2019-nCoV and their clinical and immune responses," International Journal of Research in Pharmaceutical Sciences, vol. 11, no. SPL1, pp. 62-67, 2020. 
[14] J. Grein, N. Ohmagari, D. Shin, G. Diaz, E. Asperges et al., "Compassionate use of remdesivir for patients with severe covid-19," New England Journal of Medicine, vol. 382, no. 24, pp. 2327-2336, 2020.

[15] X. T. Ye, Y. L. Luo, S. C. Xia, Q. F. Sun, J. G. Ding et al., "Clinical efficacy of lopinavir/ritonavir in the treatment of coronavirus disease 2019," European Review for Medical and Pharmacological Sciences, vol. 24, no. 6, pp. 3390-3396, 2020.

[16] P. Gautret, J. C. Lagier, P. Parola, L. Meddeb, M. Mailhe et al., "Hydroxychloroquine and azithromycin as a treatment of COVID-19: results of an open-label non-randomized clinical trial," International Journal of Antimicrobial Agents, vol. 56, no. 1, pp. 105949, 2020.

[17] Plasma Therapy Gives Positive Result in Delhi Hospital, NDTV Convergence Limited. New Delhi, India, 2020. [Online]. Available: https://swachhindia.ndtv.com/plasma-therapy-gives-positive-result-in-delhi-hospitalcoronavirus-recovered-people-can-become-donors-43583/.

[18] C. Shen, Z. Wang, F. Zhao, Y. Yang, J. Li et al., "Treatment of 5 critically ill patients with covid-19 with convalescent plasma," JAMA, vol. 323, no. 16, pp. 1582-1589, 2020.

[19] S. Jolles, "High-dose intravenous immunoglobulin (hdIVIg) in the treatment of autoimmune blistering disorders," Clinical \& Experimental Immunology, vol. 129, no. 3, pp. 385-389, 2002.

[20] W. Cao, L. Xiaosheng, B. Tao, F. Hongwei, H. Ke et al., "High-dose intravenous immunoglobulin as a therapeutic option for deteriorating patients with coronavirus disease 2019," Open Forum Infectious Diseases, vol. 7, no. 3, pp. 145-157, 2020.

[21] X. Xu, M. Han, T. Li, W. Sun, D. Wang et al., "Effective treatment of severe COVID-19 patients with tocilizumab," Proc. of the National Academy of Sciences of the United States of America, vol. 117, no. 20, pp. 10970-10975, 2020.

[22] G. Gritti, F. Raimondi, D. Ripamonti, I. Riva, F. Landi et al., "Use of siltuximab in patients with COVID-19 pneumonia requiring ventilatory support," MedRxiv, pp. 1-17, 2020. [Online]. Available: https://www.medrxiv. org/content/10.1101/2020.04.01.20048561v3.

[23] Z. Leng, R. Zhu, W. Hou, Y. Feng, Y. Yang et al., "Transplantation of ACE2- mesenchymal stem cells improves the outcome of patients with covid-19 pneumonia," Aging and Disease, vol. 11, no. 2, pp. 216-228, 2020.

[24] Y. S. Jaiswal and L. L. Williams, "A glimpse of Ayurveda-the forgotten history and principles of Indian traditional medicine," Journal of Traditional and Complementary Medicine, vol. 7, no. 1, pp. 50-53, 2017.

[25] A. K. Panda, A. K. Dixit, S. Rout, B. Mishra, U. V. Purad et al., "Ayurveda practitioners consensus to develop strategies for prevention and treatment of corona virus disease (covid-19)," Journal of Ayurveda and Integrated Medical Sciences, vol. 5, no. 1, pp. 98-106, 2020.

[26] M. Golechha, "Time to realise the true potential of Ayurveda against COVID-19," Brain, Behavior, and Immunity, vol. 87 , no. 6 , pp. 130-131, 2020.

[27] COVID-19: India, U.S. to Initiate Clinical Trials for Ayurvedic Formulations, The Hindu: Mysuru, Karnataka, India, 2020. [Online]. Available: https://www.thehindu.com/news/national/covid-19-india-us-to-initiate-clinicaltrials-for-ayurvedic-formulations/article32027859.ece/.

[28] P. L. T. Girija and N. Sivan, "Ayurvedic treatment of COVID-19/ SARS-CoV-2: A case report," Journal of Ayurveda and Integrative Medicine, Article in Press, pp. 15-30, 2020. Available at: https://pesquisa.bvsalud. org/global-literature-on-novel-coronavirus-2019-ncov/resource/en/covidwho-611984.

[29] V. Pooladanda, S. Thatikonda and C. Godugu, "The current understanding and potential therapeutic options to combat COVID-19," Life Sciences, vol. 254, no. 7, pp. 117765-117776, 2020.

[30] Ministry of AYUSH, Government of India: New Delhi, India, 2020. [Online]. Available: https://www.ayush.gov.in/.

[31] S. Saha and S. Ghosh, "Tinospora cordifolia: One plant, many roles," Ancient Science of Life, vol. 31, no. 4, pp. 151-159, 2012.

[32] D. K. Maurya, "Evaluation of yashtimadhu (glycyrrhizaglabra) active phytochemicals against novel coronavirus (SARS-CoV-2)," Research Square, Article in Press, pp. 1-18, 2020.

[33] M. Ashalatha, B. Rekha and B. Sannapannawar, “A review article on pippali (piper longum linn.)," International Ayurvedic Medical Journal, vol. 3, no. 7, pp. 1-9, 2015. 
[34] C. Khushbu, S. Roshni, P. Anar, M. Carol and P. Mayuree, "Phytochemical and therapeutic potential of piper longum Linn a review," International Journal of Research in Ayurveda and Pharmacy, vol. 2, no. 1, pp. 157$161,2011$.

[35] Ministry of AYUSH COVID Guidelines, Government of India. New Delhi, India, 2020. [Online]. Available: https://www.ayush.gov.in/docs/ayurved-guidlines.pdf.

[36] U. Lechner, "Future security: Processes or properties?- Research directions in cybersecurity," Models, Mindsets, Meta: The What, the How, and the Why Not?, vol. 11200, pp. 235-246, 2019.

[37] G. Kou, Y. Lu, Y. Peng and Y. Shi, "Evaluation of classification algorithms using MCDM and rank correlation," International Journal of Information Technology \& Decision Making, vol. 11, no. 01, pp. 197-225, 2012.

[38] G. Kou, D. Ergu, C. Lin and Y. Chen, "Pairwise comparison matrix in multiple criteria decision making," Technological and Economic Development of Economy, vol. 22, no. 5, pp. 738-765, 2017.

[39] C. N. Wang, C. Y. Yang and H. C. Cheng, "A fuzzy multicriteria decision-making (MCDM) model for sustainable supplier evaluation and selection based on triple bottom line approaches in the garment industry," Processes, vol. 7, no. 7, pp. 400-416, 2019.

[40] P. Tučník and V. Bureš, "Experimental evaluation of suitability of selected multi-criteria decision-making methods for large-scale agent-based simulations," PLoS One, vol. 11, no. 11, pp. 15-25, 2016.

[41] R. Kumar, A. I. Khan, Y. B. Abushark, M. M. Alam, A. Agrawal et al., "An integrated approach of fuzzy logic, AHP and TOPSIS for estimating usable-security of web applications," IEEE Access, vol. 8, no. 8, pp. 5094450957, 2020.

[42] A. Kumar, G. Prasad, S. Srivastav, V. K. Gautam and N. Sharma, "Efficacy and safety of guduchighanvati in the management of asymptomatic covid-19 infection: an open label feasibility study," MedRxiv, pp. 17-29, 2020.

[43] D. K. Maurya, "Evaluation of yashtimadhu (glycyrrhizaglabra) active phytochemicals against novel coronavirus (SARS-CoV-2)," Research Square, pp. 1-18, 2020.

[44] D. N. Pandey, S. Rastogi, G. G. Agarwal and S. C. Lakhotia, "Influenza like illness related clinical trial on AYUSH-64 requires cautious interpretation," Journal of Ayurveda and Integrative Medicine, Article in Press, pp. 1-26, 2020.

[45] Z. Zhang, Y. Gao and Z. Li, "Consensus reaching for social network group decision making by considering leadership and bounded confidence," Knowledge-Based Systems, vol. 204, no. 12, pp. 106240-106250, 2020.

[46] Z. Zhang, X. Kou, W. Yu and Y. Gao, "Consistency improvement for fuzzy preference relations with selfconfidence: An application in two-sided matching decision making," Journal of the Operational Research Society, Article in Press, pp. 1-14, 2020. 